\title{
Electric Power Amplification in Fusion Power Plants
}

\author{
Robert L. Hirsch
}

\section{ABSTRACT}

Fusion power concepts that are heated by electrical devices for the purpose of producing high levels of electrical output are in effect electric power amplifiers. Three systems are considered: A hypothetical electric power version of the ITER experiment, the ARIES-1 fusion reactor design, and a modified version of ARIES-1 with stainless steel structural material. We find that an ITER power plant with a reasonable electric power conversion system would produce no net electric power at its target energy amplification factor of 10 . The ARIES-1 conceptual power plant, as conceived, would have an energy amplification of 22 and an electric amplification of 6 . If stainless steel were substituted for the $\mathrm{SiC}$ composite material assumed, the ARIES-1 electric power amplification would drop to roughly 3 . We conclude that practical fusion power plants will likely require a near-ignition operating mode and qualified high temperature materials as prerequisites for commercial viability.

Keywords: ARIES, fusion, fusion power amplification, ITER, Lawson Criteria.

\author{
Published Online: December 7, 2021 \\ ISSN: $2736-5506$ \\ DOI : $10.24018 /$ ejenergy.2021.1.5.32 \\ R. L. Hirsch* \\ Management Information Services Inc, \\ Alexandria, VA, USA. \\ (e-mail: rlhirsch@comcast.net) \\ *Corresponding Author
}

\section{INTRODUCTION}

Fusion power concepts that are heated by electrical devices for the purpose of producing high levels of electrical output are in effect electric power amplifiers. Our interest is in estimates of the amplifications of a few fusion concepts from which we might draw some broad conclusions.

Electric power amplification can be defined as the electric power out of a given fusion power plant divided by the electric power into its associated electrical heating devices. Thermal energy amplification is a little less straightforward because unity amplification would require no fusion, i.e., the output would simply equal the input. Meaningful energy amplification of unity would be twice the energy output, because only then is fusion energy release equal to the energy input. This is in effect what Lawson was addressing in his 1955 report, defining fusion energy output equal to energy input [1]. In the following we disregard electric power for housekeeping (coil cooling, vacuum pumping, power to electrical storage, etc.) because it is generally projected to be comparatively small at reactor scale.

We consider three fusion systems: A hypothetical electric power version of the ITER experiment [2], the ARIES-1 fusion reactor design [3], and a modified version of ARIES1 with stainless steel structural material.

\section{TERMinOlOGY AND AsSUMPtions}

Our terminology is as follows:

$\mathrm{Q}_{\mathrm{e}}=$ Electric power amplification for the overall power plant;

$\mathrm{Q}_{\mathrm{t}}=$ Thermal power amplification due to fusion;

$\mathrm{P}_{\mathrm{ii}}=$ Electric power into the plasma heating devices;

$\mathrm{P}_{\mathrm{t}}=$ Thermal power out of the fusion core;
$P_{\mathrm{eo}}=$ Net electric power out of the overall power plant;

$\eta_{\text {he }}=$ Power plant thermal energy-to-electric power conversion efficiency;

$\eta_{\mathrm{ei}}=$ Efficiency of heating devices-to-heat energy into the plasma;

$\mathrm{P}_{\mathrm{re}}=$ Electric power out of the fusion core.

Our efficiency assumptions are $\eta_{\text {he }}=40 \%[4]$ and $\eta_{\mathrm{ei}}=50 \%$ which is in the range of "neutral beam wall plug efficiency" of 0.45-0.6 for present neutral beam systems [5] and above the "global efficiency" of the neutral beams in ITER of 26\% [6]. Clearly, these efficiencies will be larger or smaller depending on fusion concept details. For our purposes we assume steady-state operation, as opposed to the pulsed operation of ITER.

\section{CAlculations}

By definition,

1) $P_{e o}=P_{t} \eta$ he - $P_{i i}$ Electric power out of the overall power plant.

2) $Q_{t}=P_{t} / P_{i i} \eta_{e i}$ Thermal power amplification due to fusion.

3) $\mathrm{Q}_{\mathrm{e}}=\mathrm{P}_{\mathrm{eo}} / \mathrm{P}_{\mathrm{ii}}$ Electric power amplification in the overall power plant.

So,

4) $Q_{e}=Q_{t} \eta_{h e} \eta_{e i}-1$

\section{ITER AS AN Electric Power Plant}

The ITER experiment is the largest tokamak experiment ever attempted and is under construction in France [2]. Its target energy gain is $\mathrm{Q}_{\mathrm{t}} \sim 10$. If achieved, that performance would represent a dramatic increase in energy amplification relative to previous tokamak experiments. While ITER has 
many elements of a fusion power plant, it does not include equipment to convert its thermal energy output to electric power. Also, ITER will be a long-pulse system, as opposed to the more desirable steady-state operation.

If we assume steady-state operation, add an electric power conversion plant, and use our assumed efficiencies,

5) $\mathrm{Q}_{\mathrm{e}}[$ ITER $] \sim 10 \times 0.4 \times 0.5-1 \sim 1$

In other words, with our assumptions, ITER would not produce any net electric power.

\section{The Aries Conceptual Fusion Power Plant}

"The ARIES-1 study was undertaken to determine the economic, safety, and environmental potential of tokamak fusion reactors ... for achieving attractive fusion power plants." [3] Its design characteristics are as follows:

Electric power out (net) $=1000 \mathrm{MW}$;

Total thermal power $=2,544 \mathrm{MW}$;

Fusion power $=1,925 \mathrm{MW}$;

Net plant efficiency $=39 \%$;

Gross efficiency $=49 \%$;

Recirculating power fraction $=0.2$.

The listed fusion power is from the plasma only. The blanket energy contribution is given as $12 \%$, so the effective fusion power is $1,925 \times 1.12=2,156 \mathrm{MW}$. In our notations: $\mathrm{P}_{\mathrm{t}}=$ Thermal power out of the fusion core $=2,156 \mathrm{MWt}$; $\mathrm{P}_{\mathrm{eo}}=$ Electric power out of the overall power plant $=1000$ MWe;

$\mathrm{P}_{\mathrm{ii}}=$ Electric power into the plasma heating devices $=0.2 \mathrm{x}$ $1000 \mathrm{MW}=200 \mathrm{MWe}$;

$\eta_{\text {he }}=$ Heat to power conversion from the core $=49 \%$;

$\mathrm{Q}_{\mathrm{e}}=$ Electric power amplification in the overall power plant $=1200 / 200=6$.

Assuming a plasma heater efficiency $\eta_{\mathrm{ei}}=50 \%$, the thermal energy into the plasma is $200 \times 0.5=100 \mathrm{MWt}$. Thus,

$\mathrm{Q}_{\mathrm{t}} \mathrm{ARIES}=$ Thermal power gain in the plasma $=2,156 / 100$ $\sim 22$.

\section{ARIES-1 with Stainless Stell Structures}

$\mathrm{SiC}$ composites were adopted as the structural material in the ARIES-1 tokamak fusion reactor design, because of their high temperature operating potential, which could yield very high thermal power-to-electrical power conversion. With respect to $\mathrm{SiC}$ composites, we note that "Progress has been made but the fusion application is extremely challenging in that fusion-related structures (blanket modules, piping, heat exchangers, etc.) are complex, joining techniques in difficult locations will be difficult, and use in difficult, radioactive applications... [7]".

Also, "The key challenges include:

(1) understanding radiation effects (high-dose radiation and transmutation effects),

(2) development of joining technology,

(3) chemical compatibility with coolant and/or breeding materials..." and "... research will be needed to investigate interaction of hydrogen isotopes with $\mathrm{SiC}$ materials." [8] and the list of unknowns goes on.

On this basis, a very large, expensive, and time-consuming research program will be required to determine if $\mathrm{SiC}$ composites can be qualified for fusion applications. Even if such a program were to be undertaken, uncertainties will remain, because of the lack of industrial experience with these materials.

Since tokamak fusion power would involve so many newto-the-utility industry technologies, the use of stainless steels, with roughly 100 years of industrial experience, would likely to be preferred by industry for early tokamak fusion power, should that technology advance to commercialization. Accordingly, we perform a rough calculation of the ARIES1 fusion power reactor design substituting stainless to understand what the related energy penalty might be. Our assumption here is that $\eta_{\text {he }}=40 \%$, rather than the ARIES- 1 level of $49 \%$. We further assume that plasma physics will dictate the required heating power, not thermal conversion efficiency. Therefore, the required heating power will remain at $200 \mathrm{MWe}$.

\section{So,}

\section{$\mathrm{P}_{\mathrm{re}}=2,156 \times 0.4 \sim 860 \mathrm{MWe}$, rather than $1000 \mathrm{MWe}$}

$\mathrm{P}_{\mathrm{eo}}=$ the net electric power out of the overall power plant $\sim$ $860-200 \sim 660$ MWe

$\mathrm{Q}_{\mathrm{e}}=$ Electric power gain in the system $\sim 660 / 200 \sim 3.3$
$\mathrm{Q}_{\mathrm{t}}=$ Thermal power gain in the plasma $=2,156 / 100 \sim 22$

Thus, comparing the two ARIES systems, the thermal power gain in the plasma stays the same at toughly 22 , which is not surprising, because that parameter is a function of the plasma physics. On the other hand, the electric power amplification (gain) is reduced from $\sim 6$ to $\sim 3.3$.

\section{DISCUSSION AND CONCLUSION}

We know of no commercial electric power technology that operates as a direct electric power amplifier. Accordingly, there is no guidance as to the minimum level of amplification that the industry will find acceptable. Higher numbers would seem to be more attractive than lower ones, but we know of no basis for estimating future industry acceptability. In the final analysis, acceptability will undoubtedly be determined by the EPRI criteria [9]

Other conclusions:

- While ITER's target energy output-to-energy input of ten is impressive in the context of past tokamak experiments, its implied electric power amplification would be only of the order of unity. Thus, performance far beyond ITER's target will be required for potential commercial viability.

- For the ARIES-1 fusion reactor design, its electricity amplification is roughly 6 , based on the assumption that $\mathrm{SiC}$ composite structural materials will be qualified for use.

- A rough substitution of stainless steel for $\mathrm{SiC}$ composites lowers the ARIES-1 electricity amplification to roughly 3 , illustrating the importance of high temperature 
structural materials utilization for potential commercial tokamak viability.

- It was surprising that the rough-estimate electric amplifications of these systems were so low.

Finally, we believe that the evaluation of fusion reactor concepts should include explicit determination of electric power amplification to better focus on what electric utilities will value. Concepts with energy amplifications greater than 20 should be emphasized; in plasma physics terms, fusion program emphasis should probably focus on concepts that operate at near ignition, where amplifications might be higher. Also, the development and qualification of high temperature materials may be essential.

\section{FUNDING}

This work was self-funded.

\section{CONFLICT OF INTEREST}

The author declares that he has no conflict of interest.

\section{REFERENCES}

[1] Lawson JD. Some criteria for a power producing thermonuclear reactor. Proceedings of the Physical Society. Section B, 1957; 70(1): 6 .

[2] ITER.org, WHAT IS ITER? https://www.iter.org/proj/inafewlines

[3] Conn RW. Najmabadi F. ARIES-I, a steady-state, first-stability tokamak reactor with enhanced safety and environmental features. In Plasma physics and Controlled Nuclear Fusion Research 1990.1991; V: 3

[4] More than $60 \%$ of energy used for electricity generation is lost in conversion, Today in Energy, EIA, July 21, 2020.

[5] McAdams, R. Beyond ITER: Neutral beams for DEMO. arXiv preprint arXiv:1309.7185, 2013.

[6] Hemsworth RS, Boilson D, Considerations for the development of neutral beam injection for fusion reactors or DEMO, AIP Conference Proceedings 1869. 2017; 060001.

[7] Tillack MS, Holland L, Accelerated deployment of silicon carbide composites for an attractive fusion energy source, https://burningplasma.org/activities/uploads tec/m.tillack FESAC T EC2017_paper.pdf

[8] Koyanagi T, Katoh Y, Nozawa T, Snead LL, Kondo S, Henager Jr CH, et al. Recent progress in the development of $\mathrm{SiC}$ composites for nuclear fusion applications. Journal of Nuclear Materials. 2018; 511; 544-555.

[9] Kaslow J, Brown M, Hirsch R, McCann J, McCloud D, Muston B, et al. Criteria for practical fusion power systems: Report from the EPRI fusion panel. Journal of Fusion Energy. 1994; 13(2): 181-183.

Dr. R. Hirsch, Illinois, USA, 1935; BS, Mechanical Engineering, University of Illinois, 1958; MS, Nuclear Engineering, University of Michigan, 1959; Ph.D., Nuclear Engineering / Physics, University of Illinois, 1964.

He is a Senior Energy Advisor at Management Information Services, Inc. (MISI), Alexandria, VA, and a consultant in energy, technology, and management. His professional experience is in research, development, and commercial applications of energy technologies.

Previous positions include SENIOR ENERGY PROGRAM ADVISOR, SAIC (World oil production); SENIOR ENERGY ANALYST, RAND (Various energy studies); VICE PRESIDENT, ELECTRIC POWER RESEARCH INSTITUTE; VICE PRESIDENT AND MANAGER OF RESEARCH AND TECHNICAL SERVICES, Atlantic Richfield Co. (Oil and gas exploration and production technologies); FOUNDER AND CEO OF ARCO POWER TECHNOLOGIES INC. (Commercial \& Defense Department technologies); MANAGER, EXXON SYNTHETIC FUELS RESEARCH LABORATORY; MANAGER, PETROLEUM EXPLORATORY RESEARCH, EXXON RESEARCH AND ENGINEERING (Refining R \& D); ASSISTANT ADMINISTRATOR FOR SOLAR, GEOTHERMAL, AND ADVANCED
TECHNOLOGIES, U.S. Energy Research and Development Administration; DIRECTOR OF FUSION RESEARCH, U.S. Atomic Energy Commission and ERDA; PROJECT LEADER, INERTIAL ELECTROSTATIC FUSION, ITT; STAFF MEMBER, Space Nuclear Auxiliary Power, Atomic International, Inc.

He has served on an array of advisory committees for government and industry, holds 16 patents and has authored over 50 technical publications. He is past Chairman of the Board on Energy and Environmental Systems of the National Research Council, the operating arm of the National Academies of Sciences and has served on a number of National Research Council study committees. 